\title{
Extent and patterns of community collaboration in local health departments: An exploratory survey
}

\author{
James Studnicki', Elena A Platonova ${ }^{1 *}$, Chris N Eiechelberger $^{2}$ and John W Fisher ${ }^{1}$
}

\begin{abstract}
Background: Local public health departments (LHDs) in the United States have been encouraged to collaborate with various other community organizations and individuals. Current research suggests that many forms of active partnering are ongoing, and there are numerous examples of LHD collaboration with a specific organization for a specific purpose or program. However, no existing research has attempted to characterize collaboration, for the defined purpose of setting community health status priorities, between a defined population of local officials and a defined group of alternative partnering organizations. The specific aims of this study were to 1) determine the range of collaborative involvement exhibited by a study population of local public health officials, and, 2) characterize the patterns of the selection of organizations/individuals involved with LHDs in the process of setting community health status priorities.
\end{abstract}

Methods: Local health department officials in North Carolina $(n=53)$ responded to an exploratory survey about their levels of involvement with eight types of possible collaborator organizations and individuals. Descriptive statistics and the stochastic clustering technique of Self-Organizing Maps (SOM) were used to characterize their collaboration.

Results: Local health officials vary extensively in their level of collaboration with external collaborators. While the range of total involvement varies, the patterns of involvement for this specific function are relatively uniform. That is, regardless of the total level of involvement (low, medium or high), officials maintain similar hierarchical preference rankings with Community Advisory Boards and Local Boards of Health most involved and Experts and Elected Officials least involved.

Conclusion: The extent and patterns of collaboration among LHDs with other community stakeholders for a specific function can be described and ultimately related to outcome measures of LHD performance.

\section{Background}

In its landmark report of 1988, the Institute of Medicine (IOM) emphasized the importance of collaboration between public health agencies and different community stakeholders in improving community health [1]. This goal was reinforced in a 2002 IOM report that encouraged the development of collaborations representing diverse community perspectives, using community

\footnotetext{
* Correspondence: eplatono@uncc.edu

1 Department of Public Health Sciences, College of Health and Human Services, University of North Carolina, Charlotte, 9201 University City Blvd, Charlotte, NC, 28223, USA

Full list of author information is available at the end of the article
}

resources, and actively engaging the population in public health activities [2].

Collaboration with different community stakeholders is critical to meeting community health objectives [3-6] and typically involves diverse groups such as state and local health departments, federal and state agencies, community advisory boards, consumer rights and advocacy groups, as well as nonprofit organizations $[7,8]$. The primary objectives of collaboration are to leverage and expand limited resources using each partner's expertise [9-12], to reach new target populations, expand the quantity or quality of services, and prioritize community health issues using the tacit knowledge, trust, and reputation of the partners $[13,14]$.

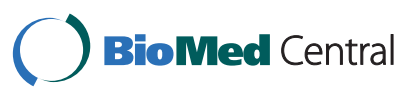


Collaboration can also unite diverse stakeholders and bring new perspectives on different public health issues in the communities $[2,15]$, make decision-making more participatory and less dominated by professionals [16], as well as to overcome political resistance from those who want less governmental involvement and control [4].

While there are extensive national hospital data, there is a relative paucity of organizational data on the public health system [17]. A number of studies indicated gaps in our understanding of the role of collaboration in public health decision-making $[7,18,19]$. Current research calls for more inquiry on participatory decision-making in public health including types of organizations and resources involved [20]. The National Association of County and City Health Officials (NACCHO), as part of the National Profile Study, has collected information about LHD collaboration with governmental and nongovernmental organizations during the period of 19902005. Respondents were asked to rate their level of collaboration from low to high on a 5-point scale for some general functional categories such as information exchange, work on a project or the provision of financial resources [21]. No existing research, however, has addressed the patterns of LHD collaboration with community partners in the process of priority setting.

Thus, the primary objective of this exploratory study is to understand the patterns of collaboration experienced by LHDs in determining the health priorities in their communities. Specifically, the study sought to 1) determine the range and patterns of involvement exhibited by local public health officials, and 2) identify the collaborating organizations/individuals and the extent of their involvement.

\section{Collaborative Involvement: Empirical Evidence from the Field}

Today's organizations access expertise through formal and informal relationships as work is becoming more interdependent and collaborative in nature [22]. The IOM 2002 report concluded that collaborations are becoming more common in public health practice [2]. A number of studies suggest that collaborations are a viable strategy as LHDs are actively partnering with different entities/stakeholders in their communities to address public health issues [6,8,23-25].

The study by Mays et al. [26] reported that about 33\% of the public health effort was contributed by community stakeholders and about half of the studied LHDs maintained support and communication networks with major community players. Another study found that diverse management teams were associated with higher LHD performance as they tended to have more extensive interactions in the community [15]. Erwin provided empirical evidence that LHD performance depended on how LHDs and their communities worked together [27]. Stoto et al identified a need for more effective public health collaboration including communication and coordination between LHDs and other community organizations engaged in crisis response to disease outbreaks [28]. Thus, there should be continued engagement of community stakeholders including private business and health care, conducting and monitoring their activities over time as well as across different levels (city, state) [29].

\section{Boards of Health}

Boards of Health are often a major contributor to local public health effort. Scutchfield et al. reported that the presence of the Boards of Health was associated with higher performance of LHDs in mobilizing communities to address public health issues [7]. Mays at al. found that perceived effectiveness of public health initiatives was $14 \%$ higher in communities that had Boards of Health than in communities without them [26]. Savoia et al. found that the presence of a Board of Health was positively associated with public health emergency preparedness activities such as conducting drills, exercises and training [30].

\section{Elected Officials}

Elected officials are often responsible for making political and public health decisions, thus, their role and influence on public health activities may be important [31]. Collaboration between elected officials and LHDs was found extremely important in making decisions regarding pharmacy sales of syringes in California [32]. Kennedy reported that higher LHD performance was associated with the perceived support by elected officials [33]. Based on the results of an empirical study, Mays et al. recommended building and maintaining a strong governmental involvement in public health systems [26].

\section{Community-Based Organizations}

Community-based organizations are typically non-profit health and social service organizations located in the communities they service. They are familiar with their communities and, as a result, represent a crucial component of the public health system for identifying community public health issues, developing responses, and assessing results $[34,35]$. Cali et al. demonstrated positive outcomes of collaboration between LHDs and academic institutions and, specifically, their combined efforts at investigating and addressing local environmental health hazards [36].

\section{Physician and Hospital Providers}

One empirical study found that medical providers were selected as major contributors to health care priority 
setting because of their deep understanding of community needs and expert knowledge necessary for decisionmaking [19]. Gadomski et al. described a number of positive initiatives resulting from collaboration between a LHD and a rural non-profit health system of community hospitals focused on preventive services [37]. Effective collaboration of LHDs with medical providers is critical because of the dynamic and quite unpredictable nature of disease outbreaks. It is important that medical providers help with disease surveillance before an outbreak occurs, and the information they provide is a critical part of outbreak identification and response [28].

\section{Community and Patient Representatives}

A number of studies found that the general public had much to contribute to public health decision-making to supplement the contribution of health care professionals and recommended intensive community involvement in public health activities $[4,19,38,39]$. For instance, projects focusing on health care information needs of Hispanic populations reported that involving Hispanic community leaders in the projects from the beginning was extremely important for the success of the projects [40]. However, evaluations of public participation in decision-making and resource allocation in public health are practically non-existent despite the increasing demands for a greater representation of communities in priority setting [41]. Communities are sometimes involved late into the project or they are merely used as informants or research subjects [2].

\section{Methods}

\section{Measures and sample}

North Carolina's 86 LHDs include large and small health departments, public health authorities, a community health alliance and district health departments which represent multiple counties. The LHDs function with the support of the state level Division of Public Health for administrative services, generalized nursing consultation, information services provided by the State Center for Health Statistics, and accreditation. As of July 2011, 61 of the LHDs have completed an accreditation process which is based upon their capacity to perform the core functions and essential services as detailed in the National Public Health Performance Standards Program. NC LHDs have interacted with boards of health, state agencies, schools, non-profit organizations, hospitals and other organizations across a variety of issues [42]. No study, however, has addressed the nature and extent of collaboration in the process of determining community health status priorities.

The paper survey was administered to NC LHD directors or their representatives during regular monthly meetings of NC health officers in the fall of 2007. The institutional review board (IRB) of the University of North Carolina, Charlotte, approved the project protocol and survey instrument prior to data collection. Respondents consented to the use of the data, including publication of the findings, with the promise of anonymity and confidentiality. Fifty-three respondents completed the surveys, representing 62 percent of all NC local public health directors. Respondents were given a list of eight types of organizations/individuals as follows: Health Department Staff, Local Boards of Health, Patient Representatives, Community Advisory Board, Community Health Professionals (physicians, hospital administrators), Elected Officials, Community-based Organizations (United Way), and Experts. Respondents were asked to rate the level of involvement with each of the organizations/individuals on a scale from 1 (to a very little extent) to 7 (to a very great extent).

\section{Analysis}

The analysis had three components. First, an average score was calculated for each of the eight collaborator (individuals/organizations) categories. This score was the accumulated ratings (maximum possible $7 \times 53=$ 371) of involvement levels (1-7) for each collaborator category divided by the number of respondents (maximum possible $=7$ ). Second, a total involvement score was calculated for each of the 53 local public health officials. This score was the sum of all collaborator ratings (maximum possible $7 \times 8=56$ ). Health official involvement scores were segmented into two groups at the approximate midpoint: low involvers $(\mathrm{n}=26)$ and high involvers $(n=27)$ and their scores were distributed among three categories of involvement extent responses (scores 1-2, scores 3-5, scores 6-7).

Third, the technique of Self-Organizing Maps (SOM) was applied to the data. SOM is a data visualization technique which reduces the dimensions in a data set and displays similarities among the data objects as groups or clusters. Essentially, we were probing to identify clusters of health officials in regard to their involvement choices and levels; and, clusters of organizations/ individuals collaborators in regard to their patterns of selection by health officials. The SOM is a stochastic clustering technique that distributes data across a grid $(3 \times 3$ cells in this case $)$ so that neighboring instances within a grid cell are likely to be more similar to each other than to instances that are associated with other grid cells [43]. The grid cell definitions adapt over the course of many iterations (training) and every instance is compared to all grid cells and a best match identified. Over the course of iterations the learning rate, how much each instance is allowed to alter its best match, is lowered, allowing the system to settle into an equilibrium, thus producing the clusters. 


\section{Results}

\section{Involvement levels: Organizations/Individuals}

The internal Health Department Staff received the highest average level of involvement score in the health problems priority setting (6.06) (Table 1). This interorganizational finding was expected since it was anticipated that every local public health unit would rely heavily on internal staff resources in this process. This score also served as a benchmark for the seven intraorganizational scores for other organizations/individuals in order to provide a comparative range of values. Three organizations were clustered together with average involvement scores between 4.50 and 4.85: Community Advisory Boards, Community Health Professionals, and Local Boards of Health. Community-based Organizations (4.13) and Patient Representatives (4.02) had the next highest level of involvement. Elected Officials (3.66) and Experts (2.13) were the least involved by local public health officials in the process of determining community health status priorities.

\section{Involvement levels: Health officers}

Health official total involvement scores ranged from 12 to 51 (mean $=33.89$, median $=34.0$, mode $=40.00, \mathrm{SD}$ $=8.19$ ). Health officials with scores between 12 and 33 were placed in the Low involvement group and those with scores between 34 and 51 were placed in the High involvement group. Low involvers placed a higher proportion of their responses than did High involvers in the intermediate response category (scores 3-5) for four types of organizations/individuals: Health Department Staff, Local Boards of Health, Community Advisory Board, and Community Health Professionals. For three types of organizations, the Low involvers placed a lower proportion of their responses in the intermediate response category: Elected Officials, Community-based Organizations, and Experts. For Patient Representatives, both Low and High involvers placed a nearly identical percentage of responses in the intermediate category (Table 2). Overall, 50\% of the Low involver responses fell into the intermediate category compared to $38 \%$ of the responses of the High involvers.

\section{Table 1 Average involvement scores}

\begin{tabular}{ll}
\hline Organizations/Individuals & Mean (SD) \\
\hline Health Department Staff & $6.06(1.39)$ \\
Local Board of Health & $4.85(2.02)$ \\
Community Health Professionals & $4.60(1.66)$ \\
Community Advisory Board & $4.55(1.55)$ \\
Community-based Organizations & $4.13(1.94)$ \\
Patient Representatives & $4.02(1.66)$ \\
Elected Officials & $3.66(1.56)$ \\
Experts & $2.13(1.81)$ \\
\hline
\end{tabular}

Low involvers selected low involvement scores (scores 1 and 2) more than three times as frequently as High involvers (36\% vs. 11\%, respectively), but High involvers selected high involvement scores (scores 6 and 7) nearly four times as frequently as Low involvers (50\% vs. 13\%). Not even a single High involver selected a low involvement score for Community-Based Organizations or Community Health Professionals even though Low involvers selected those response categories $50 \%$ and $27 \%$ of the time, respectively. By contrast, no Low involver selected a high involvement score for Community Health Professionals or Elected Officials, while High involvers did so $70 \%$ and $19 \%$ of the time, respectively. The high involvement responses (scores 6 and 7) represented only $13 \%$ of the Low involvers responses but $50 \%$ of the High involvers responses. These Low/High comparisons indicated a greater tendency for a generalized response among highly involved health officers than for the low involvement group. In other words, high involvement is more generalized, low involvement is more selective.

\section{SOMs}

The SOM technique produced three clusters of health officers whose arrangement appears to correspond generally to the overall involvement scores: upper left cell grid location; high involvement, $\mathrm{n}=19$; upper center cell grid location, medium involvement, $\mathrm{n}=14$; and, lower right cell grid location, low involvement, $\mathrm{n}=20$. The relative positions of these three clusters are displayed in Figure 1.

The three clusters exhibit a characteristic shape in regard to organization/individual collaborations. The least amount of difference among the three clusters is at the extremes; i.e. where there is the highest involvement (Health Department Staff) and the lowest involvement (Experts). For only a single organizational category (i.e. Community-based Organizations) do we see a relatively higher level of involvement for the medium involvement group than for the high involvement group, and the difference is very small. The greatest apparent distance between the high and medium involvement groups is for collaboration with the Local Board of Health.

The SOM technique also produced four clusters from the eight organizational/individual categories identified in the survey (Figure 2). In this case, the data are used to identify the similarities between the organizational types and to reduce the number of types in an attempt to understand the patterns of collaboration. The four clusters were composed as follows: Community Advisory Board and Health Department Staff; Communitybased Organizations and Community Health Professionals; Local Boards of Health; and, Experts, Elected Officials and Patient Representatives. 
Table 2 Health official involvement extent scores by low and high involvers*

\begin{tabular}{|c|c|c|c|c|c|c|}
\hline \multirow[t]{3}{*}{$\begin{array}{l}\text { Organizations/individuals involved in priority } \\
\text { setting }\end{array}$} & \multicolumn{2}{|c|}{$\begin{array}{l}\text { Involvement extent (scores } \\
1 \& 2 \text { ) }\end{array}$} & \multicolumn{2}{|c|}{$\begin{array}{l}\text { Involvement extent (scores } \\
3-5 \text { ) }\end{array}$} & \multicolumn{2}{|c|}{$\begin{array}{l}\text { Involvement extent (scores } \\
6 \text { \& 7) }\end{array}$} \\
\hline & Low-In ${ }^{\S}$ & High-In ${ }^{\ddagger}$ & Low-In ${ }^{\S}$ & High-In ${ }^{\neq}$ & Low-In ${ }^{\S}$ & High-In ${ }^{\neq}$ \\
\hline & $\mathrm{n}=75$ & $\mathrm{n}=25$ & $n=105$ & $\mathrm{n}=83$ & $\mathrm{n}=\mathbf{2 8}$ & $n=108$ \\
\hline Health Department Staff & $\begin{array}{l}2(3 \%) \text { column } \\
\text { (8\%) row }\end{array}$ & $0(0 \%)(0 \%)$ & $\begin{array}{l}11(10 \%) \\
(42 \%)\end{array}$ & $1(1 \%)(4 \%)$ & $\begin{array}{l}13(36 \%) \\
(50 \%)\end{array}$ & $\begin{array}{l}26(24 \%) \\
(96 \%)\end{array}$ \\
\hline Local Board of Health & $4(5 \%)(15 \%)$ & $2(8 \%)(7 \%)$ & $\begin{array}{l}20(19 \%) \\
(77 \%)\end{array}$ & $\begin{array}{l}12(14 \%) \\
(44 \%)\end{array}$ & $2(7 \%)(8 \%)$ & $\begin{array}{l}13(13 \%) \\
(48 \%)\end{array}$ \\
\hline Patient Representatives & $8(11 \%)(31 \%)$ & $3(12 \%)(11 \%)$ & $\begin{array}{l}15(14 \%) \\
(58 \%)\end{array}$ & $\begin{array}{l}16(19 \%) \\
(59 \%)\end{array}$ & $3(11 \%)(11 \%)$ & $8(7 \%)(30 \%)$ \\
\hline Community Advisory Board & 7 (9\%) (27\%) & $2(8 \%)(7 \%)$ & $\begin{array}{l}12(11 \%) \\
(46 \%)\end{array}$ & $5(6 \%)(18 \%)$ & $7(25 \%)(27 \%)$ & $\begin{array}{l}20(19 \%) \\
(74 \%)\end{array}$ \\
\hline Community Health Professionals & 7 (9\%) (27\%) & $0(0 \%)(0 \%)$ & $\begin{array}{l}19(18 \%) \\
(73 \%)\end{array}$ & $8(10 \%)(30 \%)$ & $0(0 \%)(0 \%)$ & $\begin{array}{l}19(18 \%) \\
(70 \%)\end{array}$ \\
\hline Elected Officials & $\begin{array}{l}12(16 \%) \\
(46 \%)\end{array}$ & $2(8 \%)(7 \%)$ & $\begin{array}{l}14(13 \%) \\
(54 \%)\end{array}$ & $\begin{array}{l}20(24 \%) \\
(74 \%)\end{array}$ & $0(0 \%)(0 \%)$ & $5(5 \%)(19 \%)$ \\
\hline Community-Based Organizations & $\begin{array}{l}13(17 \%) \\
(50 \%)\end{array}$ & $0(0 \%)(0 \%)$ & $\begin{array}{l}11(10 \%) \\
(42 \%)\end{array}$ & $\begin{array}{l}14(17 \%) \\
(52 \%)\end{array}$ & $2(7 \%)(8 \%)$ & $\begin{array}{l}13(12 \%) \\
(48 \%)\end{array}$ \\
\hline Experts & $\begin{array}{l}22(29 \%) \\
(85 \%)\end{array}$ & $\begin{array}{l}16(64 \%) \\
(59 \%)\end{array}$ & $3(3 \%)(11 \%)$ & $7(8 \%)(26 \%)$ & $1(4 \%)(4 \%)$ & $4(4 \%)(15 \%)$ \\
\hline
\end{tabular}

* Row and column percents do not always add to $100 \%$ due to rounding.

$\S$ Low-involvers

‡ High-involvers

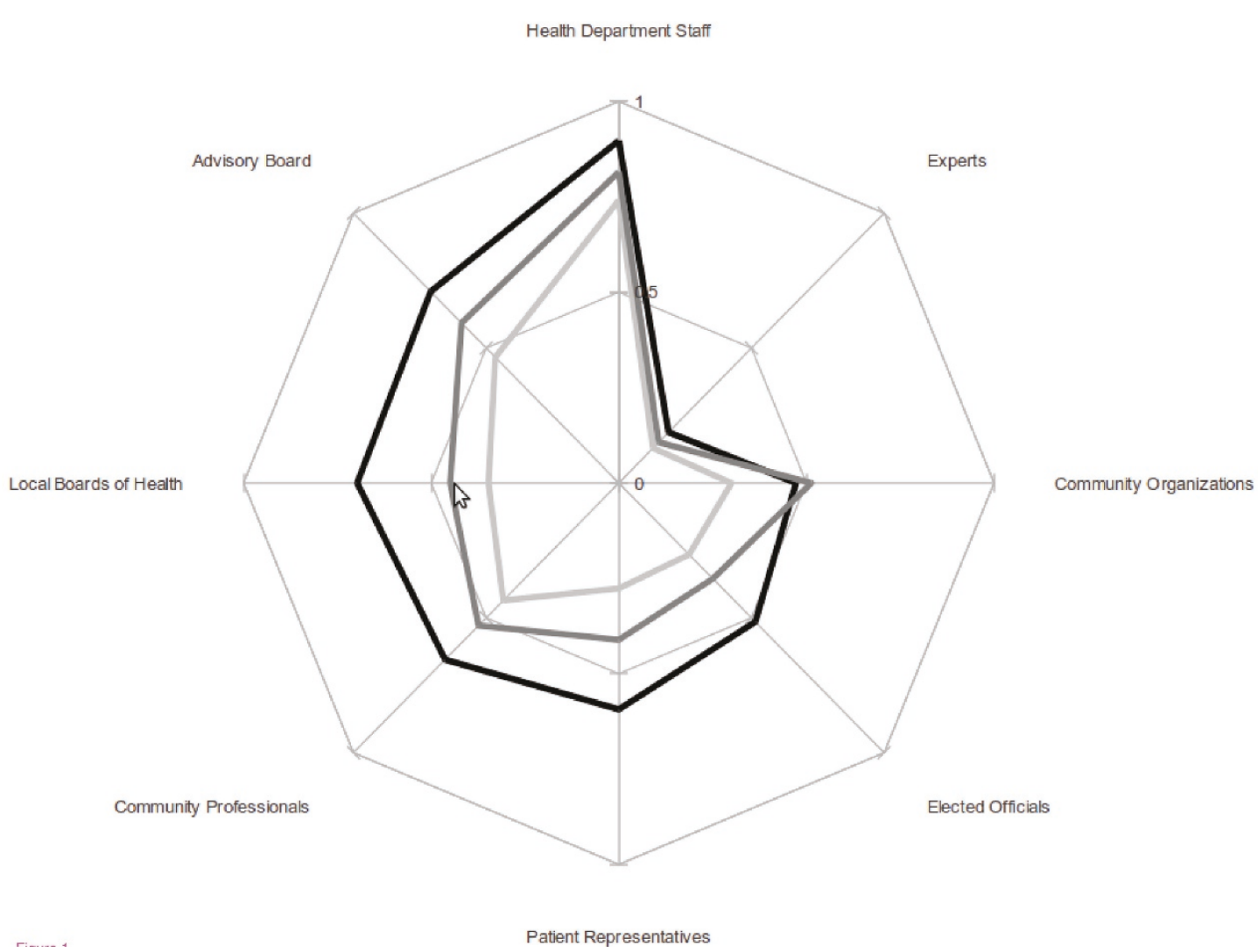

Figure 1 Three involvement level clusters for $\mathbf{8}$ collaborator organizations/individuals. Health official involvement levels: Black line high Grey line medium Light grey line low Source: Authors 


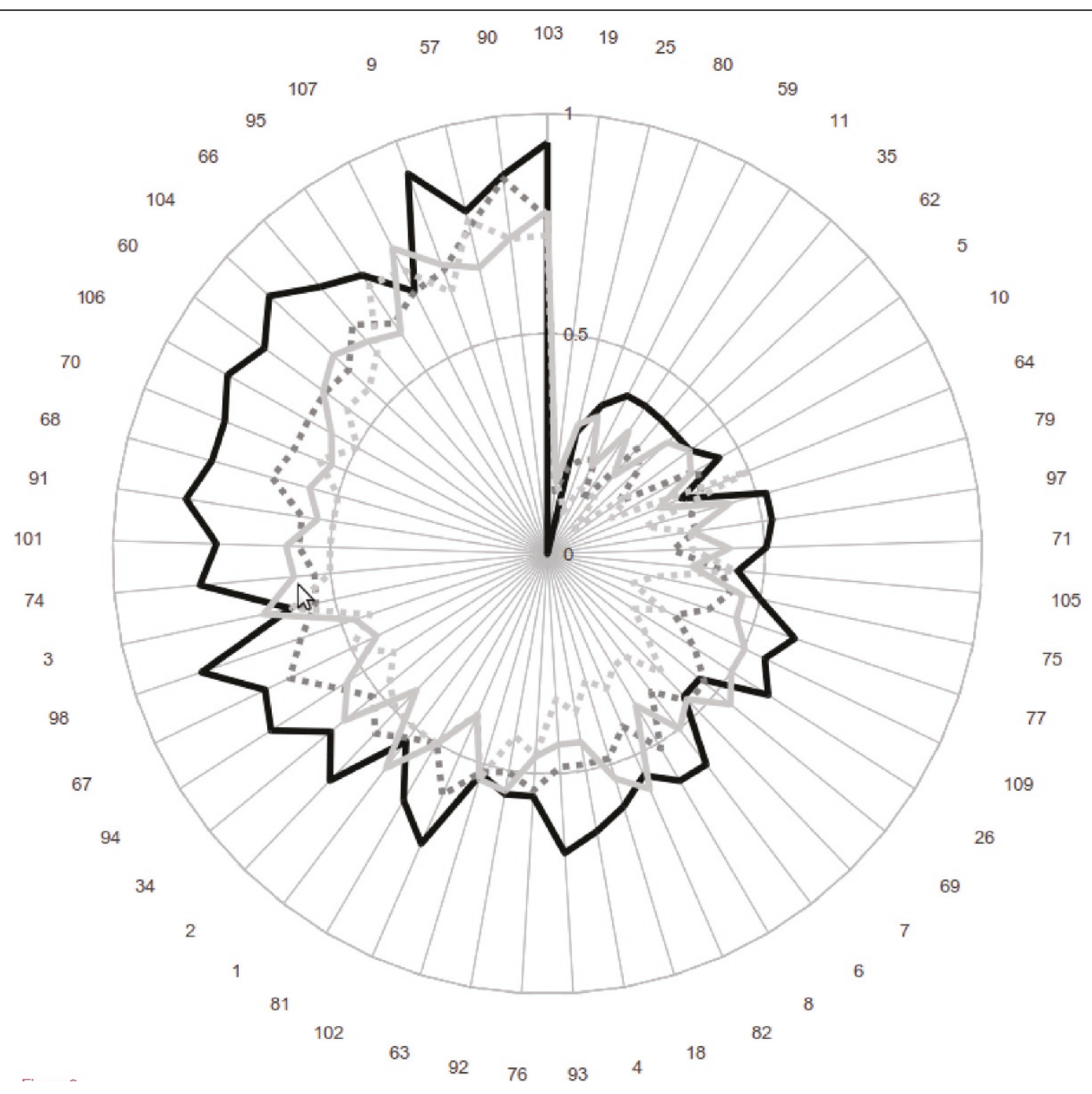

Figure 2 Four collaboration clusters for $\mathbf{5 3}$ health officials. Organization/individual clusters: Solid black line Advisory Board, Health Department Staff Solid light grey line Local Boards of Health Broken grey line Community Organizations/Professionals Broken light grey line Experts, Elected Officials, Patient Representatives Source: Authors

Note that individual respondents in Figure 2 are organized in a clockwise fashion from lowest to highest total involvement. For most of the range of responses, Health Department Staff and Community Advisory Board are the most prominent collaborators in priority setting. The Local Board of Health collaboration, although not quite as prominent overall, is strongest in the low medium ranges of total involvement, occasionally approaching or eclipsing that of the Health Department Staff. Community-Based Organizations and Community Health Professionals are more prominently involved with medium and high level involved public health officials. Experts, Elected Officials, and Patient Representatives were the least involved across the complete spectrum of total involvement.

\section{Discussion}

Local public health officials exhibit a wide range of involvement with collaborators in the priority setting process, from very little involvement with any organization to extensive involvement with multiple organizations. There is a hierarchy of collaborator organizations/ individuals with Community Advisory Boards/Local Boards of Health and Community Health Professionals most likely to be involved and Experts and Elected Officials least likely to be involved. Despite the variation in level of involvement among health officials, the patterns of preference for collaboration are relatively uniform; i.e. low, medium and highly involved officials maintain the same preference ranking among the eight collaborator types with only some minor variation. Officials agree most closely about both the least involved (Experts) and 
most involved (Health Department Staff) collaborators. Local Boards of Health appear to be most involved in the low to medium ranges of total involvement.

A number of the findings, although descriptive and without the benefit of multidimensional analyses because of data limitations, are noteworthy. The relatively low involvement with Elected Officials is somewhat surprising in that the case could be made that priority setting for resource allocation decisions may be the most important function of local government. Since LHDs in NC and many other states must often cobble together a budget derived from multiple sources, it seems the highest levels of collaborative decision making with county and city officials during this process would be advisable. Yet, only 5 of the responding officials indicated a high level of involvement with elected officials, and the SOM technique clustered Elected Officials, Experts and Patient Representatives together as the least preferred partners for collaboration. It should be noted that there may be structural characteristics which could partially account for the low level of LHD/elected officials' collaboration on health priorities such as the formal budgeting and appropriation processes involved and the prohibition of lobbying activities between government employees and elected officials.

Local Boards of Health emerged as an important influence in NC LHD priority setting. This role was further emphasized by the SOM placement of the Local Boards in their own separate cluster, indicating a unique association with local health officials. Local Boards of Health are advisory and/or governance bodies to LHDs within $\mathrm{NC}$ which promote the concept of citizen involvement in the local public health system as members of Local Boards of Health. Though largely voluntary and unpaid, the Boards have an obviously high profile among the LHDs for activities involving the core functions and essential services of public health. North Carolina is one of only 14 states with an Affiliated State Association of Local Boards of Health. The Local Boards of Health exhibit the highest levels of collaboration with the health officials who exhibit low to medium levels of involvement. This pattern may be an indication of the important role played by these voluntary organizations in smaller communities lacking the social capital and other resources and agencies found in more urbanized, developed areas.

The hierarchy of collaborator organizations/individuals is apparent despite the variation in the level of involvement among health officials. An important question is whether this uniform hierarchy of preferences is specific to the function, process or problem which is the object of collaborative activity? Are Experts, for example, more likely to be involved in collaborative activity with LHDs for program evaluation than seems to be the case for priority setting?

There are a number of limitations to this research which must be considered in interpreting the results. This is a study sample of 53 local public health officials in a single state (NC) and we have no comparison information for the nonrespondents. Similarly, as the result of the promise of anonymity to respondents, no information concerning health officer and community characteristics was available to use as correlates in further interpreting the extent and patterns of collaboration identified. Perhaps most importantly, due to the lack of defined health status or management outcomes, these results cannot in any way be used to characterize the performance of these health officials.

\section{Conclusions}

These exploratory analyses have demonstrated both a range of involvement in collaboration among local health officials and a uniform pattern of collaborator preferences for one specific process; i.e. selecting community health status priority problems. Future research into the value of collaboration with community stakeholders continues to be dependent on the ability to establish valid outcome measures to determine, and empirically measure, whether the extent and pattern of collaboration results in a better selection of priorities. One approach would be to assess the "strategic congruence" of the specified priorities, or the extent to which the priorities are consistent with quantitative comparative measures of local population health status [44]. In other words, is collaboration more likely to produce a set of priorities that are evidence-based? This is an important question since many local public health functions are legally mandated or resulting from funding decisions made at the national and state levels. Similarly, community and health officer characteristics seem likely to influence the extent and nature of collaboration and are important elements to include in future research.

Ultimately, the extent and patterns of collaboration with external community partners should be informed by the degree to which that activity can be positively associated with defined community level outcomes such as desired changes in service utilization and costs and, most importantly, morbidity and mortality.

\section{Author details}

${ }^{1}$ Department of Public Health Sciences, College of Health and Human Services, University of North Carolina, Charlotte, 9201 University City Blvd, Charlotte, NC, 28223, USA. ${ }^{2}$ College of Computing and Informatics, University of North Carolina, Charlotte, 9201 University City Blvd, Charlotte, NC, 28223, USA. 


\section{Authors' contributions}

JS and EAP contributed to conception and design of the study, acquisition of data, interpretation of results, drafting and reviewing the manuscript and final approval of the version to be published. CNE contributed to interpretation of results, drafting sections of the manuscript and final approval of the version to be published. JWF contributed to acquisition of data, drafting sections of the manuscript and final approval of the version to be published.

\section{Competing interests}

The authors declare that they have no competing interests.

Received: 30 August 2011 Accepted: 7 October 2011

Published: 7 October 2011

\section{References}

1. Institute of Medicine: The future of public health. Washington (DC): National Academy Press; 1988.

2. Institute of Medicine: The future of public's health in the $21^{\text {st }}$ century. Washington (DC): National Academy Press; 2002.

3. Beitsch L, Corso L: Accountability: the fast lane on the highway to change. Am J Public Health 2009, 99(9):1545

4. Brownson R, Fielding J, Maylahn C: Evidence-based public health: a fundamental concept for public health practice. Annu Rev Public Health 2009, 30:175-201.

5. Cava M: Is public health ready for a professional practice framework? J Health Serv Res Policy 2008, 13(Suppl 1):57-63.

6. Daley D: Interdisciplinary problems and agency boundaries: exploring effective cross-agency collaboration. Journal of Public Administration and Theory 2008, 19(3):477-93.

7. Scutchfield FD, Knight EA, Kelly AV, Bhandari MW, Vasilescu IP: Local Public health agency capacity and its relationship to public health system performance. J Public Health Manag Pract 2004, 10(3):204-15.

8. Zahner S: Local public health partnerships. Public Health Reports 2005, 120(January-February):76-83.

9. Bailey S: Focusing on solid partnerships across multiple sectors for population health improvement. Prev Chronic Dis 2010, 7(6)[http://www. cdc.gov/pcd/issues/2010/nov/pdf/10_0126.pdf].

10. Benjamin G, Lopez W, Monson A: Partners in public health law: elected officials, health directors, and attorneys. J Law Med Ethics 2002, 30(3):17-21

11. Simon P, Fielding J: Public health and business: partnership that makes sense. Health Aff (Millwood) 2006, 25(4):1029-39.

12. Wholey D, Cregg W, Moscovice I: Public health systems: a social networks perspective. Health Serv Res 2009, 44(5 Pt II):1842-62.

13. Mays G, Scutchfield FD: Improving public health system performance through multiorganizational partnerships. Prev Chronic Dis 2010, 7(6) [http://www.cdc.gov/pcd/issues/2010/nov/pdf/10_0088.pdf].

14. Wei-Skillern J: Networks as a type of social entrepreneurship to advance population health. Prev Chronic Dis 2010, 7(6)[http://www.cdc.gov/pcd/ issues/2010/nov/pdf/10_0082.pdf].

15. Lovelace K: Multidisciplinary top management teamwork: effects on local health department performance. J Public Health Manag Pract 2001, 7(1):21-9.

16. Wiseman V, Mooney G, Berry G, Tang K: Involving the general public in priority setting: experiences from Australia. Soc Sci Med 2003, 56:1001-12.

17. Scutchfield FD, Mays GP, Lurie N: Applying health services research to public health practice: an emerging priority. Health Serv Res 2009, 44(5 Pt II): $1775-87$

18. Mays G, McHugh M, Shim K, Perry N, Lenaway D, Halverson P, Moonesinghe R: Institutional and economic determinants of public health system performance. Am J Public Health 2006, 96(3):523-31.

19. McKie J, Shrimpton B, Hurworth R, Bell C, Richarson J: Who should be involved in health care decision making? A qualitative study. Health Care Anal 2008, 16:114-26.

20. Woulfe J, Oliver T, Zahner S, Siemering K: Multisector partnerships in population health improvement. Prev Chronic Dis 2010, 7(6)[http://www. cdc.gov/pcd/issues/2010/nov/pdf/10_0082.pdf].

21. The National Profile of Local Health Departments Study Series, National Association of County and City Health Officials - NACCHO:[http://www. naccho.org/topics/infrastructure/profile/].
22. Parise S: Knowledge management and human resource development: an application in social network analysis methods. Advances in Developing Human Resources 2007, 9(3):359-83.

23. Connor A, Rainer L, Simcox J, Thomisee $K$ : Increasing the delivery of health care services to migrant farm worker families through a community partnership model. Public Health Nurs 2007, 24(4):355-60.

24. Kegler M, Painter J, Twiss J, Aronson R, Norton B: Evaluation findings on community participation in the California healthy cities and communities program. Health Promot Int 2009, 24(3):300-10.

25. Pescosolido B: Of pride and prejudice: the role of sociology and social networks in integrating the health sciences. J Health Soc Behav 2006, 47(September):189-208.

26. Mays $G$, Halverson P, Baker E, Stevens R, Vann J: Availability and perceived effectiveness of public health activities in the nation's most populous communities. Am J Public Health 2004, 94(6):1019-26.

27. Erwin P: The Performance of local health departments: review of the literature. J Public Health Manag Pract 2008, 14(2):E9-E18.

28. Stoto M, Dausey D, Davis L, Leuschner K, Lurie N, Myers S, Olmsted S, Ricci K, Ridgely S, Sloss E, Wasserman J: Learning from experience: the public health response to West Nile virus, SARS, Monkeypox, and Hepatitis A outbreaks in the United States 2005., Rand Corporation: Health Report: XI-XXV.

29. Fawcett S, Schultz J, Watson-Thompson J, Fox M, Bremby R: Building multisectoral partnerships for population health and health equity. Prev Chronic Dis 2010, 7(6)[http://www.cdc.gov/pcd/issues/2010/nov/pdf/ 10_0079.pdf].

30. Savoia E, Rodday A, Stoto M: Public health emergency preparedness at the local level: results of a national study. Health Serv Res 2009, 44(5 Pt II): 1909-24.

31. Mays $\mathrm{G}$, Smith $\mathrm{S}$ : Geographic variation in public health spending: correlates and consequences. Health Serv Res 2009, 44(5 Part II):1796-817.

32. Backs G, Rose V: Primary and secondary analysis of local elected officials' decisions to support or oppose pharmacy sale of syringes in California. $J$ Urban Health 2010, 87(4):553-60.

33. Kennedy V: A study of local public health system performance in Texas. J Public Health Manag Pract 2003, 9(3):183-7.

34. Parker E, Israel B, Williams M, Brakefield-Caldwell W, Lewis T, Robins T, Ramirez E, Rowe Z, Keeler G: Community action against asthma: examining the partnership process of a community-based participatory research project. J Gen Intern Med 2003, 18:558-67.

35. Richter D, Potts L, Prince M, Dauner K, Reininger B, Thompson-Robinson M, Corwin $S$, Getty $C$, Jones R: Development of a curriculum to enhance community-based organization's capacity for effective HIV prevention programming and management. AIDS Educ Prev 2006, 18(4):362-74.

36. Cali S, Scheff P, Mucha A, Nickels L, Oliynyk I, Hryhorrczuk D: The Great Lakes Center's health hazard evaluation program: promoting community environmental health through partnerships between academic and public health departments. J Environ Health 2007, 70(1):42-6.

37. Gadomski A, Wicks D, Abernethy K, Lewis C, Pearson T: Providing preventive services in a rural area through a public-private partnership. Am J Public Health 1997, 87(8):1375-6.

38. Bruni $R$, Laupacis A, Levinson W, Martin D: Public involvement in the priority setting activities of a wait time management initiative: a qualitative case study. BMC Health Serv Res 2007, 7:186[http://www. biomedcentral.com/content/pdf/1472-6963-7-186.pdf].

39. Litva A, Coast J, Donovan J, Eyles J, Shepperd M, Abelson J, Morgan K: "The public is too subjective": public involvement at different levels of health-care decision making. Soc Sci Med 2002, 54:1825-37.

40. Ruffin A, Gogdill K, Kutty L, Hudson-Ochillo M: Access to electronic health information for the public: analysis of fifty-three funded projects. Libr Trends 2005, 53(3):434-52.

41. Mitton C, Smith N, Peacock S, Evoy B, Abelson J: Public participation in health care priority setting: a scoping review. Health Policy 2009, 91:219-28.

42. Lovelace K: External collaboration and performance: North Carolina Local Public Health Departments. Public Health Reports 2000, 115:350-357.

43. Kohonen T: Self-Organizing Maps New York: Springer-Verlag; 1997.

44. Studnicki J: Evaluating the performance of public health agencies: information needs. Am J Prev Med 1995, 11(6):74-80, Research and Measurement in Public Health Practice Supplement. 
doi:10.1186/1756-0500-4-387

Cite this article as: Studnicki et al:: Extent and patterns of community collaboration in local health departments: An exploratory survey. BMC Research Notes 2011 4:387.

Submit your next manuscript to BioMed Central and take full advantage of:

- Convenient online submission

- Thorough peer review

- No space constraints or color figure charges

- Immediate publication on acceptance

- Inclusion in PubMed, CAS, Scopus and Google Scholar

- Research which is freely available for redistribution

Submit your manuscript at www.biomedcentral.com/submit 